\section{Dams: test pros and cons case by case}

Mike Muller argues that dams can produce clean, cheap energy while shrinking or eliminating methane-emitting wetlands downstream (Nature 566, 315-317; 2019). This hypothesis is untested and should not shape decisions that could affect large regions for centuries.

Setting aside the societal and ecological impacts of shrinking natural wetlands, we find Muller's argument problematic from the perspective of greenhouse-gas budgeting. Floodplain wetlands typically hold large stores of carbon. Disrupting the hydrology that caused these accumulations over millennia could lead to the sustained release of carbon as $\mathrm{CO}_{2}$, potentially counteracting any reduction in methane emissions.

Furthermore, emissions from hydropower are site-specific, depending on reservoir and catchment characteristics, among other factors (L. Scherer and S. Pfister PLoS ONE 11, e0161947; 2016). Although some hydropower reservoirs have low net life-cycle emissions, others generate large amounts of greenhouse gases.

Evaluating the pros and cons of dams will therefore require holistic, evidence-based accounting of their impact on greenhouse-gas emissions, ecology and society - on a case-by-case basis.

John A. Harrison* Washington State University, Vancouver, Washington, USA.

john_harrison@wsu.edu ${ }^{*}$ On behalf of 13 signatories (see go.nature.com/f41tt1 for full list).

\section{Dams: keep wetland damage in check}

Given the global importance and fragile status of wetlands and rivers, proposals for more dams must be carefully evaluated so as not to compromise human well-being and biodiversity.
In his enthusiasm for using hydropower to generate renewable energy and cut greenhouse-gas emissions, Mike Muller overlooks the disruption by dam construction to the huge socio-economic and ecological value of wetlands (Nature 566, 315-317; 2019).

The extent of natural wetlands has decreased by more than 35\% over the past 50 years or so, as a result of dam construction and land transformation (see go.nature.com/2uezpvu). This loss cannot be offset by an increase in artificial wetlands of lower biodiversity, such as rice paddies and reservoirs, as Muller suggests.

Wetlands are crucial for conserving the diversity of freshwater species, whose numbers have declined by more than $80 \%$ since 1970 (see go.nature.com/2tj2jhs). Dam projects already curtail fish catches that provide the main source of protein for millions of people in the floodplains of the Mekong River. And dams can do little to prevent methane emissions from the most important wetland sources, such as those in areas of permafrost thaw.

We must ensure that the collateral damage of hydropower programmes does not cancel out their benefits.

Virgilio Hermoso Forest Sciences Centre of Catalonia, Solsona, Spain.

Miguel Clavero, Andy J. Green Doñana Biological Station EBD-CSIC, Seville, Spain. virgilio.hermoso@gmail.com

\section{Sex is a variable in the brain too}

We are concerned that Lise Eliot's review of Gina Rippon's book The Gendered Brain (Nature 566, $453-454$; 2019) undermines the premise that sex is a biological variable with respect to many medical conditions and drug responses (see J. A. Clayton and F. S. Collins Nature 509, 282 283 ; 2014).
As president-elect and president, respectively, of the Organization for the Study of Sex Differences, we disagree with Eliot's claim that the brain is "no more gendered than the liver or kidneys or heart”. We also disagree that sex differences in behaviour are due to cultural effects on newborns, not to biological effects. In our view, these are not mutually exclusive. Sex disparities occur in animal models that are not subject to cultural bias.

The brain, like many organs, shows differences attributable to sex, both during health (see, for example, E. Luders et al. J. Neurosci. 29, 14265-14270; 2009) and during disease. Two-thirds of people with Alzheimer's disease are women; twice as many men as women have Parkinson's disease (see, for example, L. J. Young and D. W. Pfaff Front. Neuroendocrinol. 35, 253-254; 2014). And multiple sclerosis affects three times more women than men, although men with the condition develop neurological disability more quickly (see, for example, R. R. Voskuhl and S. M. Gold Nature Rev. Neurol. 8, 255-263; 2012). Sex is a modifier of disease risk and progression.

Studying the effects of sex differences in health and disease will lead to new treatments that target sex hormone and sex-chromosome effects. These will ultimately help people irrespective of their sex.

Rhonda Voskuhl University of California, Los Angeles, USA. Sabra Klein Johns Hopkins University, Baltimore, Maryland, USA.

rvoskuhl@mednet.ucla.edu

\section{Don't hush up Munk's sonic test}

In my view, any recollection of oceanographer Walter Munk's long string of accomplishments (see C. Wunsch Nature 567, $176 ; 2019)$ should note that these were marred by one huge, ecologically risky experiment.

In January 1991, Munk ran a feasibility test of acoustic tomography near Heard Island in the Indian Ocean, whence sound waves would propagate through all the world's oceans (A. Baggeroer and W. Munk Phys. Today 45, 22-30; 1992). The plan was to project sound horizontally at an intensity of 221 decibels, at a depth of 100 metres, where the SOFAR acoustic channel would act as a sonic wave guide. The sound would be pulsed, with one hour on and two hours off.

Because of concerns about the effects of this unprecedented level of acoustic energy on marine mammals worldwide, the project needed a permit for "limited harassment" of whales (J. Cohen Science 252, 912-914; 1991). Such was Munk's influence that the permit, requested from the US National Oceanic and Atmospheric Administration on 15 October 1990, was granted on 7 December and revised 3 days later to increase the number of animals that could be harassed from 10 cetaceans to 234,200, and from 100 pinnipeds to 115,000 .

These ocean creatures were intermittently subjected to this excessively loud sound source for five days (subsequent studies based on the results of this test aimed to reduce the sound intensity by $20 \mathrm{~dB}$ ). Munk's hasty and scientifically naive experiment was one of the largest ever conducted on the world.

Thomas J. Murphy DePaul University, Chicago, Illinois, USA. tmurphy@depaul.edu

\section{CORRECTION}

The Correspondence piece 'Speed up mapping of soil pollution' (Nature 566, 455; 2019) erroneously stated that the fifth UNEA session will take place in 2020. It is, in fact, planned for 2021. 